\title{
Pengukuran Arah Kiblat Masjid Syaikh Zainuddin Nahdhatul Wathan Bintan
}

\author{
M. Arbisora Angkat ${ }^{1 *}$, Rizki Pradana Hidayatullah ${ }^{2}$ \\ 1, 2, STAIN Sultan Abdurrahman Kepulauan Riau, Bintan, Kepulauan Riau, 29123, Indonesia \\ *arbisora_angkat@stainkepri.ac.id
}

\begin{abstract}
Abstrak
Pengabdian Masyarakat adalah kegiatan civitas akademika yang memanfaatkan ilmu pengetahuan dan teknologi untuk memajukan kesejahteraan masyarakat dan mencerdaskan kehidupan bangsa. Civitas akademika dalam hal ini dosen dituntut harus mampu bersosialisasi dengan masyarakat dan mampu berkontribusi nyata. Salah satu bentuk pengabdian masyarakat yang dilakukan adalah pengukuran arah kiblat terhadap masjid-masjid yang ada. Pengukuran arah kiblat menggunaan ilmu pengetahuan dan teknologi merupakan sebuah usaha dalam memantapkan ibadah shalat. Semakin akurat pengukuran arah kiblat maka semakin mantap keyakinan dalam melakukan sholat. Pondok Pesantren Syaikh Zainuddin Nahdlatul Wathan Bintan merupakan Pondok Pesantren yang berada di bawah naungan organisasi Nahdlatul Wathan yang didirikan oleh Maulana Syaikh TGKH. Muhammad Zainuddin Abdul Madjid, seorang Pahlawan Nasional dari Lombok - Nusa Tenggara Barat. Pondok ini merupakan kategori pondok baru dan sedang membangun berbagai macam fasilitas pondok termasuk masjid. Pengukuran arah kiblat Masjid Syaikh Zainuddin dilakukan pada tanggal 11 Februari 2021 dengan data lintang tempat $01^{\circ}$ 0.84' LS, bujur tempat $104^{\circ} 30.67^{\prime}$ BT menggunakan Instrumen Falak yaitu Aulatis. Posisi arah kiblat Masjid Syaikh Zainuddin adalah $23^{\circ}$ 03' 8.82" dari titik Barat miring ke arah Utara atau $66^{\circ} 56^{\prime} 51.18^{\prime \prime}$ dari titik Utara miring ke arah Barat atau Azimut Kiblat 29303'08.82" UTSB (Utara Timur Selatan Barat).
\end{abstract}

Kata kunci: Arah Kiblat; Syaikh Zainuddin; Nahdhatul Wathan.

\begin{abstract}
Community Dedication is an activity of the academic community that utilizes science and technology to advance the welfare of the community and educate the nation's life. The academic community, in this case the lecturers, is required to be able to socialize with the community and be able to make a real contribution. One form of community service carried out is measuring the Qibla direction towards existing mosques. The measurement of the Qibla direction using science and technology is an attempt to strengthen the prayer service. The more accurate the measurement of the Qibla direction, the more stable the belief in praying. Syaikh Zainuddin
\end{abstract}


Nahdlatul Wathan Bintan Islamic Boarding School is an Islamic Boarding School under the auspices of the Nahdlatul Wathan organization which was founded by Maulana Syaikh TGKH. Muhammad Zainuddin Abdul Madjid, a National Hero from Lombok - West Nusa Tenggara. This Islamic Boarding School is a new Islamic Boarding School category and is currently building various facilities including a mosque. The measurement of the Qibla direction of the Syaikh Zainuddin Mosque was carried out on February 11, 2021 with latitude data 01o 0.84' south latitude, longitude 104o 30.67' east longitude using the Falak Instrument, namely Aulatis. The position of the Qibla direction of the Syaikh Zainuddin Mosque is 23o 03' 8.82"' from the West point tilted to the North or 660 56'51.18" from the North point tilted to the West or Qibla Azimut 293o 03'08.82" UTSB (North East South West).

Keywords: Qibla Direction, Syaikh Zainuddin, Nahdhatul Wathan.

\section{Pendahuluan}

Menghadap kiblat adalah salah satu di antara perkara yang menjadi syarat sahnya ibadah shalat. Ini sudah merupakan kesepakatan para ulama bahwa menghadap kiblat dalam melaksanakan shalat hukumnya adalah wajib, karena merupakan salah satu syarat syah shalat, sebagaimana yang terdapat dalam dalil-dalil syara' (Izzudin, 2006). Arah kiblat seakan-akan bagaikan navigator buat umat muslim di dunia untuk menyembah Tuhannya, kesalahan dalam menghadap arah kiblat bagaikan kehilangan arah untuk menyembah Tuhan.

Ka'bah sebagai arah kiblat sebenarnya merupakan sejarah yang paling tua di dunia. Bahkan jauh sebelum Allah Swt menciptakan manusia di bumi, Allah SWT telah mengutus para malaikat untuk turun ke bumi dan membangun rumah pertama tempat ibadah manusia, yaitu Ka'bah (Izzudin A, 2006). Sebagaimana yang telah tercantum dalam Al-Quran;

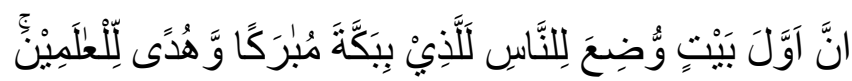

Artinya: "Sesungguhnya rumah (ibadah) pertama yang dibangun untuk manusia ialah (Baitullah) yang di Bakkah (Mekkah) yang diberkahi dan menjadi petunjuk bagi seluruh alam." (QS. Ali Imran : 96) (Departemen Agama RI, 2005).

Dalam pembangunan Ka'bah Nabi Ismail as menerima Hajar Aswad (batu hitam) dari Jibril di Jabal Qubais, lalu meletakkannya di sudut tenggara bangunan. Bangunan itu berbentuk kubus yang dalam bahasa arab disebut muka'ab. Dari kata inilah muncul sebutan Ka'bah. Ketika itu Ka'bah belum berdaun pintu dan belum ditutupi kain (Azhari, 2007).

Pada masa Nabi Muhammad SAW, awalnya perintah shalat itu mengarah ke Baitul Maqdis di Palestina. Tetapi Rasulullah SAW berusaha agar shalat tetap menghadap ke Ka'bah yaitu dengan cara mengambil posisi di sebelah selatan Ka'bah kemudian menghadap ke utara, maka selain menghadap Baitul Maqdis beliau juga tetap menghadap Ka'bah.

Namun setelah Rasulullah SAW tiba di Madinah selama 16 atau 17 bulan terus menerus menghadap ke Baitul Maqdis sehingga mengalami kesulitan untuk menghadap ke dua tempat yang berlawanan arah. Rasulullah SAW sangat mengharapkan supaya Allah SWT memerintahnya menghadap ke Ka'bah, karena Ka'bahlah kiblat Nabi Ibrahim AS. Nabi Muhammad SAW tidak langsung memohon perpindahan itu, beliau hanya mengharap-harap datangnya perintah Allah SWT (Ash-Shiddieqy, 2003). Hingga turunlah ayat berikut: 


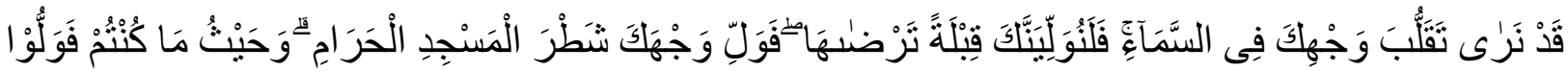

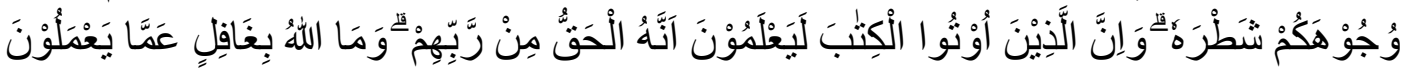

Artinya : "Kami melihat wajahmu (Muhammad) sering menengadah ke langit. Maka akan Kami palingkan engkau ke kiblat yang engkau senangi. Maka hadaplah wajahmu ke arah Masjdil Haram. Dan dimana saja engkau berada hadapkanlah wajahu kearah itu. Dan sesungguhnya orang-orang yang diberi Kitab (Taurat dan Injil) tahu bahwa (pemindahan kiblat) itu adalah kebenaran dari Tuhan mereka. Dan Allah tidak lengah dari apa yang mereka kerjakan.” (Q.S Al Baqarah ayat : 144).

Oleh karena itu, sebelum seseorang hendak melakukan shalat, terlebih dahulu harus memenuhi syarat-syaratnya, baik itu syarat wajibnya maupun syarat sahnya. Salah satunya adalah harus yakin dan sadar bahwa arah kiblatnya sudah benar (Romdhon dan Angkat, 2021).

Para ulama sepakat bahwa menghadap kiblat dalam melaksanakan shalat hukumnya adalah wajib karena merupakan salah satu syarat shalat, sebagaimana yang terdapat dalam dalil-dalil syara'. Orang yang berada dekat dengan kiblat (Ka'bah), menurut pendapat yang ashah, wajib menghadap kiblat secara nyata dan tepat, menghadapkan semua anggota badannya ke kiblat. Apabila dia menyimpang dari Ka'bah secara nyata, maka shalatnya tidak sah. Bagi orang yang berada di Mekkah dan sekitarnya, persoalan tersebut tidak ada masalah, karena mereka lebih mudah dalam melaksanakan kewajiban itu (Zuhaili, 2010).

Bahkan yang menjadi persoalan adalah bagi orang yang jauh dari Mekkah, kewajiban seperti itu merupakan hal yang berat, karena mereka tidak pasti bias mengarah ke Ka'bah secara tepat, bahkan para ulama berselisih mengenai arah yang semestinya. Sebab mengarah ke Ka'bah yang merupakan syarat sahnyashalat adalah menghadap Ka'bah yang haqiqi atau sebenarnya (Angkat, 2016).

Kepala Laboratorium Boscha Bandung Taofik Hidayat mengatakan, keraguan arah kiblat Masjid terjadi di beberapa daerah di Indonesia. Penetapan arah kiblat bangunan masjid dan mushalla lama menggunakan cara-cara tradisional yakni memedomani arah terbenamnya matahari. Hal itu dilakukan karena ketika itu memang belum ada peralatan canggih seperti sekarang ini, sehingga tidak sulit lagi untuk menentukan arah kiblat yang lebih akurat.

Kalau ditilik dari lintasan sejarah, cara penentuan arah kiblat di Indonesia dari masa ke masa memang mengalami perkembangan sesuai dengan perkembangan ilmu pengetahuan yang dimiliki oleh masyarakat Islam Indonesia itu sendiri. Selain itu perhitungan yang dipergunakan juga mengalami perkembangan, baik mengenai data koordinat maupun sistem ilmu ukurnya (Izzudin, 2007).

Oleh karena itu, untuk mempermudah dan membantu umat Islam dalam menghadap ke arah kiblat, maka sangat dibutuhkan kontribusi Ilmu Falak dalam hal ini, terkait jauhnya jarak antara Ka'bah dan Indonesia sehingga menyebabkan banyaknya masjid-masjid yang tidak tepat menghadap ke arah kiblat. Sehingga Pengurus Pondok Pesantren Syaikh Zainuddin Nahdlatul Wathan Bintan meminta bantuan kepada Dosen STAIN Sultan Abdurrahman Kepulauan Riau untuk melakukan pengukuran terhadap Masjid Syaikh Zainuddin yang akan segera dibangun. Sehingga nantinya dapat diketahui arah kiblat Masjid Syaikh Zainuddin, dan dalam praktiknya akan menggunakan ilmu pengetahuan dan peralatan yang lebih modern sehingga dapat memperoleh keakurasian yang mendekati kebenaran, agar lebih memantapkan keyakinan warga Pondok Pesantren Syaikh Zainuddin Nahdlatul Wathan Bintan dalam beribadah.

\section{Metode}

Metode yang digunakan dalam pengabdian kepada masyaraka di Pondok Pesantren Syaikh Zainuddin Nahdlatul Wathan Bintan menggunakan metode konsultasi. Metode konsultasi digunakan untuk kegiatan- 
kegiatan yang di dalamnya persoalan atau kebutuhan dalam masyarakat diselesaikan melalui sinergisme dengan Perguruan Tinggi. Persoalan di Pondok Pesantren Syaikh Zainuddin Nahdlatul Wathan Bintan adalah masjid yang belum diukur arah kiblatnya, sehingga dibutuhkan pengukuran arah kiblat terhadap Masjid Syaikh Zainuddin yang akan segera dibangun.

Pondok Pesantren Syaikh Zainuddin Nahdlatul Wathan Bintan menjadi objek pengabdian karena adanya permintaan dari Bapak Saepuddin, M.Ag selaku Ketua Pondok Pesantren Syaikh Zainuddin Nahdlatul Wathan Bintan untuk mengukur arah kiblat masjid mereka. Karena Pondok Pesantren Syaikh Zainuddin Nahdlatul Wathan Bintan ingin membangun sebuah masjid yang akan dijadikan sebagai sarana beribadah. Pengukuran arah kiblat Masjid Syaikh Zainuddin dilakukan dalam rangka memantapkan keyakinan warga Pondok Pesantren Syaikh Zainuddin Nahdlatul Wathan Bintan dalam beribadah.

Lokasi Pondok Pesantren Syaikh Zainuddin Nahdlatul Wathan Bintan berada di Kabupaten Bintan. Sebagaimana data yang diperoleh bahwa di Bintan setiap tahunnya terdapat permohonan pengukuran arah kiblat. Menurut keterangan Kemenag Bintan, setiap tahun selalu ada permohonan untuk kalibrasi kiblat masjid dan mushalla. Pada tahun 2019, telah dilakukan 20 kalibrasi kiblat terhadap masjid di Bintan yakni, 6 musholla Sekolah, 2 musholla Pondok Pesantren, 1 Musholla Kantor, 7 Musholla di lingkungan masyarakat, 4 Mesjid, dan 1 lokasi di Hotel RIA Bintan Golf Club Lagoi. 1 lokasi kalibrasi pengukuran arah kiblat di Hotel RIA ini terdiri dari pengukuran arah kiblat untuk setiap kamar Hotel, Mesjid, Musholla tempat istirahat, dan Musholla untuk Karyawan Putra dan Putri (Kepri.kemenag.go.id, 2021). Sedangkan pada tahun 2020, terdapat 10 lokasi yang dilakukan kalibrasi kiblat di antaranya dua rumah ibadah tersebut adalah Masjid Besar Kecamatan Mantang yang berlokasi di Jalan Lapangan Bola Desa Mantang dan Musala Kantor Camat Mantang (Kepri.kemenag.go.id, 2021).

Tim pengabdi berpartisipasi secara langsung dalam persoalan yang ada di Pondok Pesantren Syaikh Zainuddin Nahdlatul Wathan Bintan terkait dibutuhkannya pengukuran arah kiblat Masjid Syaikh Zainuddin. Kegiatan pengukuran arah kiblat dilaksanakan menggunakan Instrumen Falak yaitu Aulatis. Sedangkan untuk perhitungan arah kiblat pengabdi menggunakan software arah kiblat Wa Auqotis Shalat Aulatis, sehingga mempermudah pengabdi dalam melakukan perhitungan arah kiblat kiblat Masjid Syaikh Zainuddin.

\section{Hasil dan Pembahasan}

Pondok Pesantren Syaikh Zainuddin Nahdlatul Wathan Bintan merupakan cabang dari Pondok Pesantren Syaikh Zainuddin Nahdlatul Wathan Anjani Lombok Timur Nusa Tenggata Barat. Nama pondok pesantren ini diambil dari nama pendiri Nahdhatul Wathan yaitu Maulana Syaikh TGKH. Muhammad Zainuddin Abdul Madjid yang lebih sering dipanggil Syaikh Zainuddin. Beliau adalah tokoh pelopor pendidikan dan perjuangan di Nusa Tenggata Barat, dan atas jasanya beliau dianugerahkan gelar Pahlawan Nasional oleh Presiden Joko Widodo tahun 2017 yang lalu. Pada tahun 1943 beliau mendirikan lembaga pendidikan perdana yang disebut Nahdhatul Wathan Diniyah Islamiyah (NWDI) dan selanjutnya mendirikan Organisasi Nahdhatul Wathan yang bergerak di bidang pendidikan, sosial dan dakwah islamiyah. Hingga saat ini Nahdhatul Wathan telah mendirikan ribuan sekolah/madrasah dan pondok pesantren di seluruh Indonesia (Saepuddin, 2021).

Pondok Pesantren Syaikh Zainuddin Nahdhatul Wathan Bintan beralamat di Jalan Lintas Barat Km.22

Desa Toapaya Kec.Toapaya Kab.Bintan Prov. Kepulauan Riau (2 KM dari Kampus STAIN Sultan Abdulrahman Kepri). Pondok Pesantren Syaikh Zainuddin Nahdhatul Wathan Bintan menggunakan kurikulum terpadu antara Kurikulum Diknas dan Kurikulum Pondok Pesantren. Disini santri akan dibina, dididik serta dilatih dan dibentuk menjadi generasi yang SMART (Shalih, Mandiri, Alim, Religius dan Terampil) dengan dibekali jiwa kepemimpinan dan entrepreneurship. Pondok Pesantren Syaikh Zainuddin Nahdlatul Wathan Bintan memiliki program unggulan seperti hafiz quran, kitab kuning, bahasa Arab \& Inggris serta entrepreneurship. Pondok Pesantren Syaikh Zainuddin Nahdlatul Wathan Bintan dipimpin oleh Bapak Saepuddin, M.Ag, beliau merupakan Kepala Prodi Manajemen Pendidikan Islam di STAIN Sultan 
Abdurrahman Kepulauan Riau. Pondok Pesantren Syaikh Zainuddin Nahdlatul Wathan Bintan juga memiliki tenaga pengajar dari S1 dan S2 lulusan perguruan tinggi dalam dan luar negeri serta alumni pondok pesantren ternama. Pondok Pesantren Syaikh Zainuddin Nahdlatul Wathan Bintan juga memiliki kegiatan ekstrakulikuler seperti pencak silat, kaligrafi, public speaking, berkebun, memanah, hadroh dan pramuka.

Dari semua jadwal kegiatan santri diatas notabene dilakukan di masjid, karena masjid merupakan sarana dan media dakwah yang sangat penting. Masjid juga sebagai tempat ibadah umat muslim terutama ibadah sholat. Masjid Pondok Pesantren Syaikh Zainuddin Nahdlatul Wathan Bintan diberi nama sesuai dengan nama pondoknya yaitu Masjid Syaikh Zainuddin, masjid tersebut juga masih dalam proses pengumpulan dana dari para donator. Oleh sebab itu sebelum proses pembangunan Masjid Syaikh Zainuddin perlu dilakukan pengukuran arah kiblat terhadap masjid tersebut agar memantapkan keyakinan dalam beribadah termasuk ibadah sholat.

Untuk menjawab tantangan zaman yang serba maju, Pondok Pesantren Syaikh Zainuddin Nahdlatul Wathan Bintan dirancang menggunakan konsep belajar perpaduan antara Tradisi Pesantren dan Pendidikan Islam Modern. Konsep ini dimaksudkan agar para santri dapat belajar dengan baik, dan mendapatkan pemahaman ilmu keagamaan yang mendalam serta membentuk ahklak yang mulia. Selain itu, diharapkan para santri memiliki skill, kemandirian serta wawasan leadership dan enterpreneur, sehingga memungkinkan dirinya mampu memberikan manfaat yang besar bagi kemajuan agama, masyarakat, bangsa dan negara. Tentunya semua kegiatan santri tersebut harus didukung oleh fasilitas yang memadai termasuk sebuah masjid. Masjid menjadi sarana yang sangat vital bagi sebuah pondok pesantren, karena disanalah notabene kegiatan banyak dilakukan terutama ibadah sholat.

Masjid Syaikh Zainuddin berada pada lintang tempat $01^{\circ} 0.84^{\prime}$ LS, bujur tempat $104^{\circ} 30.67^{\prime}$ BT. Pengukuran arah kiblat Masjid Syaikh Zainuddin Nahdlatul Wathan Bintan dilakukan pada tanggal 11 Februari 2021 oleh Dosen STAIN Sultan Abdurrahaman Kepulauan Riau menggunakan Instrumen Falak yaitu Aulatis. Alat ini mirip seperti Mizwala Qibla Finder yang merupakan karya dari Bapak Hendro Setyanto. Aulatis merupakan singkatan dari alat ukur kiblat praktis, oleh karena itu alat ini dikategorikan sebagai salah satu metode yang praktis dalam mengukur arah kiblat.

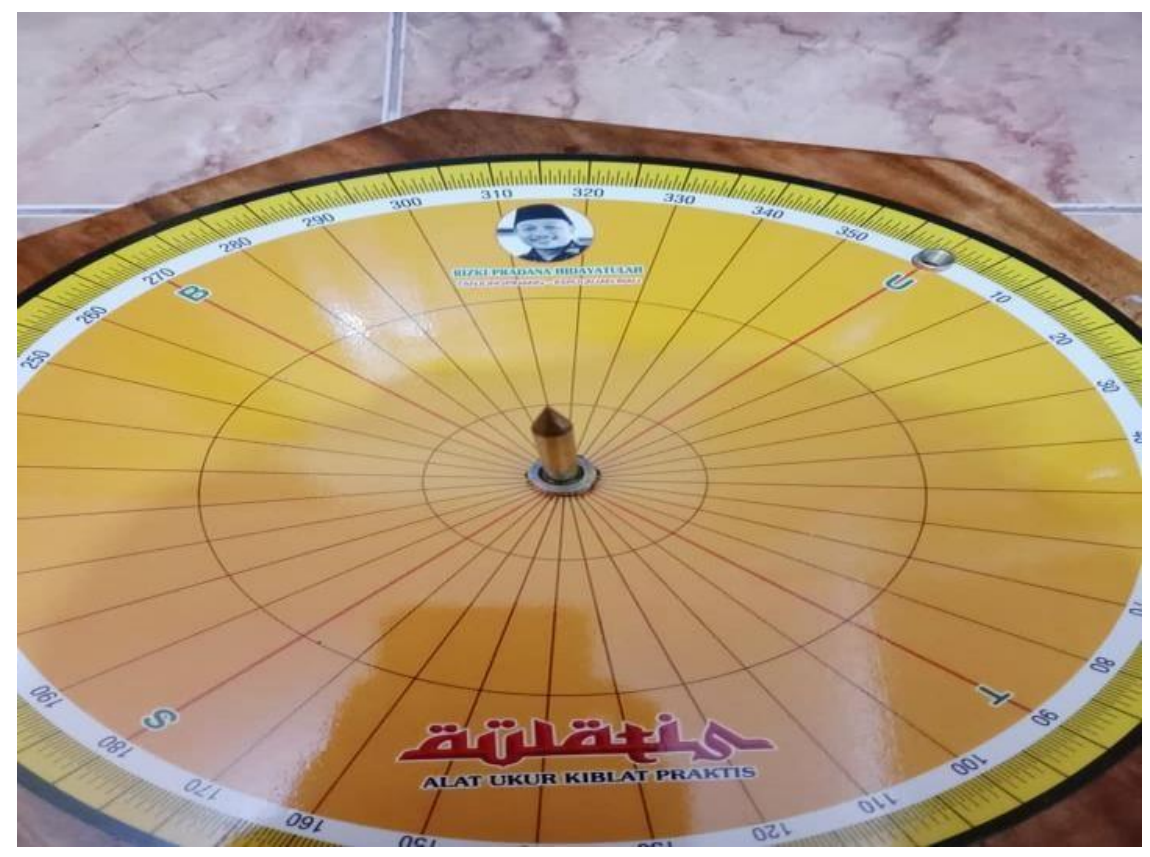

Gambar 1. Aulatis (Alat Ukur Kiblat Praktis) 
Sebelum masuk ke dalam proses pengukuran arah kiblat perlu dilakukan perhitungan arah kiblat terlebih dahulu. Dalam penggunaannya Aulatis juga termasuk mudah, hanya membutuhkan sinar matahari. Apabila dalam kondisi cuaca tidak cerah/mendung maka alat ini tidak dapat digunakan. Dalam proses perhitungan alat ini juga sudah dilengkapi dengan software, sehingga dalam proses perhitungan hanya memasukkan data tanggal, jam serta lintang dan bujur tempat yang ingin dihitung. Ketika semua data tersebut dimasukkan, maka akan keluar hasil data perhitungan arah kiblat yang lengkap.

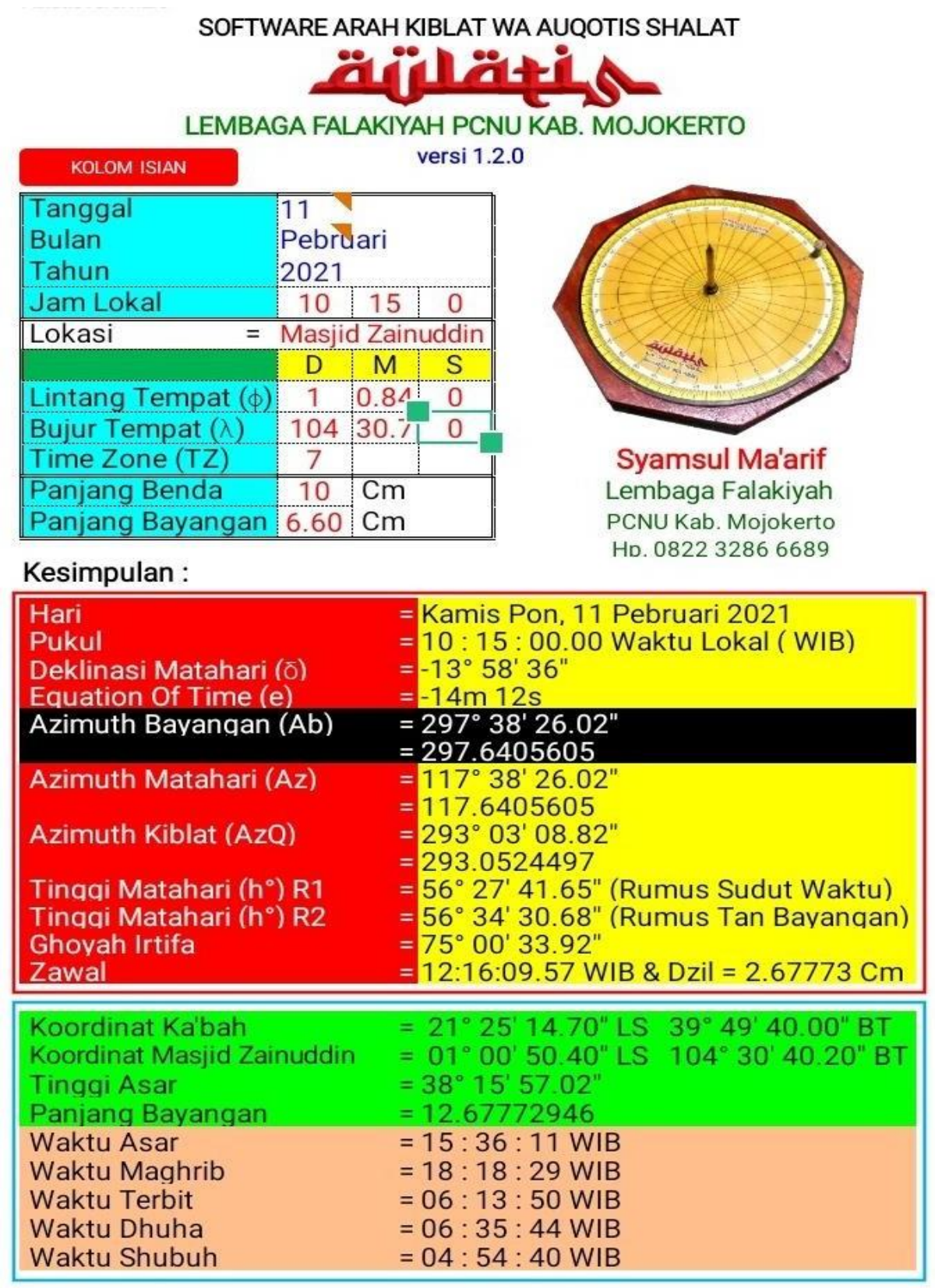

Gambar 2. Hasil Data Arah Kiblat Menggunakan Software Arah Kiblat Aulatis (Ma'arif)

Posisi arah kiblat Masjid Syaikh Zainuddin adalah $23^{\circ} 03^{\prime}$ 8.82" dari titik Barat miring ke arah Utara atau 66 56' 51.18" dari titik Utara miring ke arah Barat atau Azimut Kiblat 293 03'08.82" UTSB (Utara Timur Selatan Barat). Pengukuran arah kiblat Masjid Syaikh Zainuddin Nahdlatul Wathan Bintan disaksikan langsung oleh Bapak Saepuddin, M.Ag selaku Ketua Pondok Pesantren Syaikh Zainuddin Nahdlatul Wathan Bintan. 


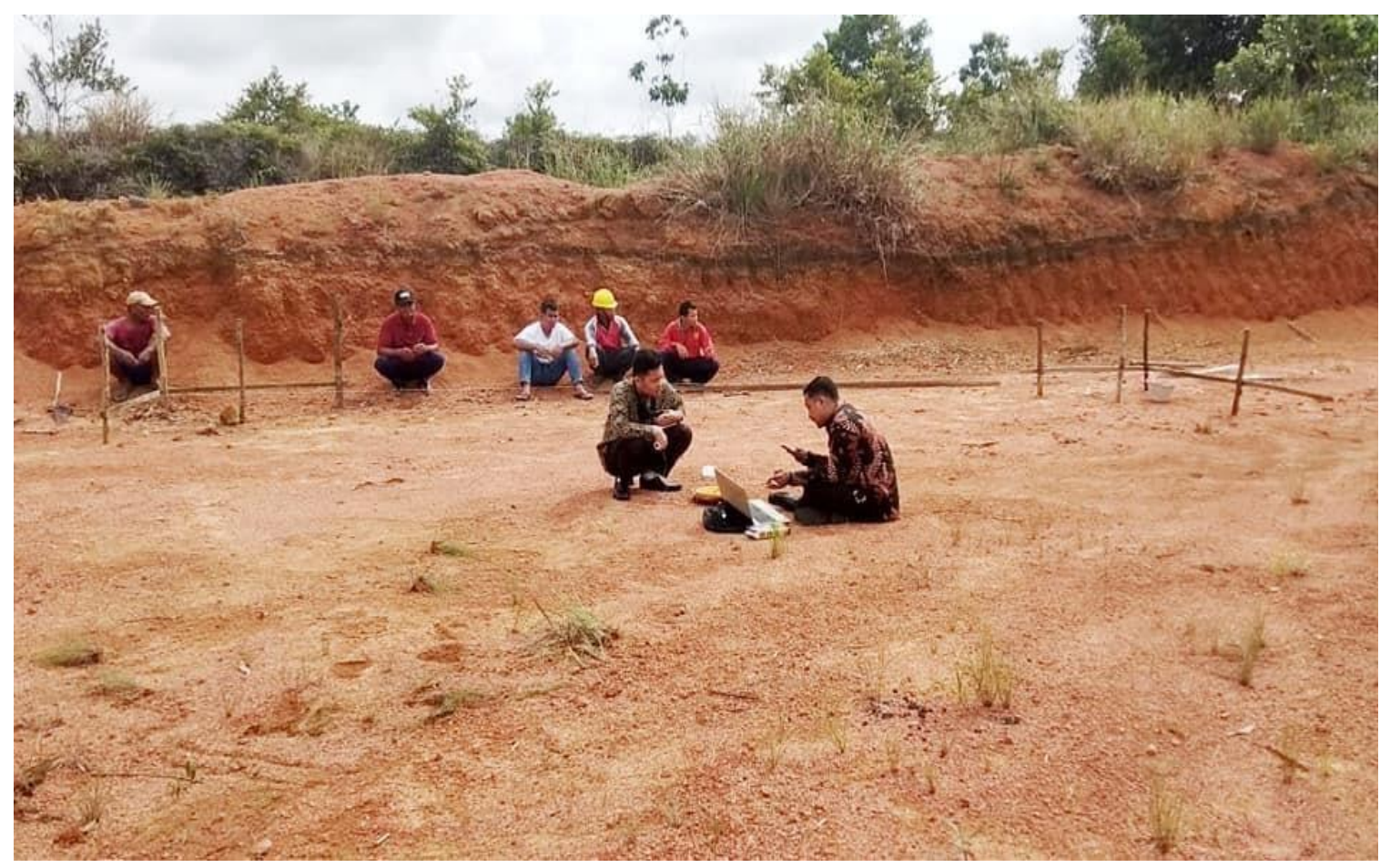

Gambar 3. Proses perhitungan arah kiblat Masjid Syaikh Zainuddin

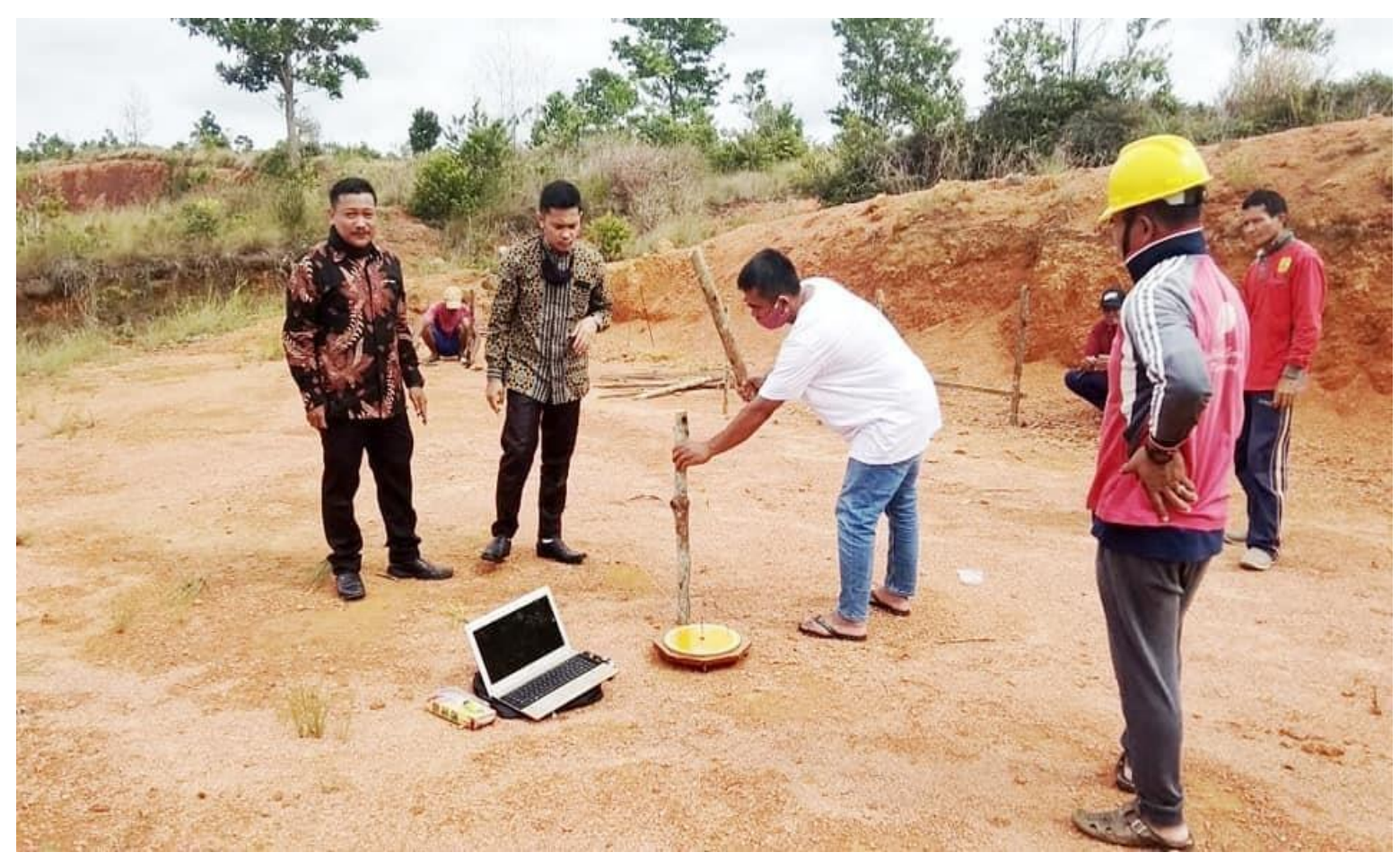

Gambar 4. Pemasangan tiang patokan arah kiblat Masjid Syaikh Zainuddin 


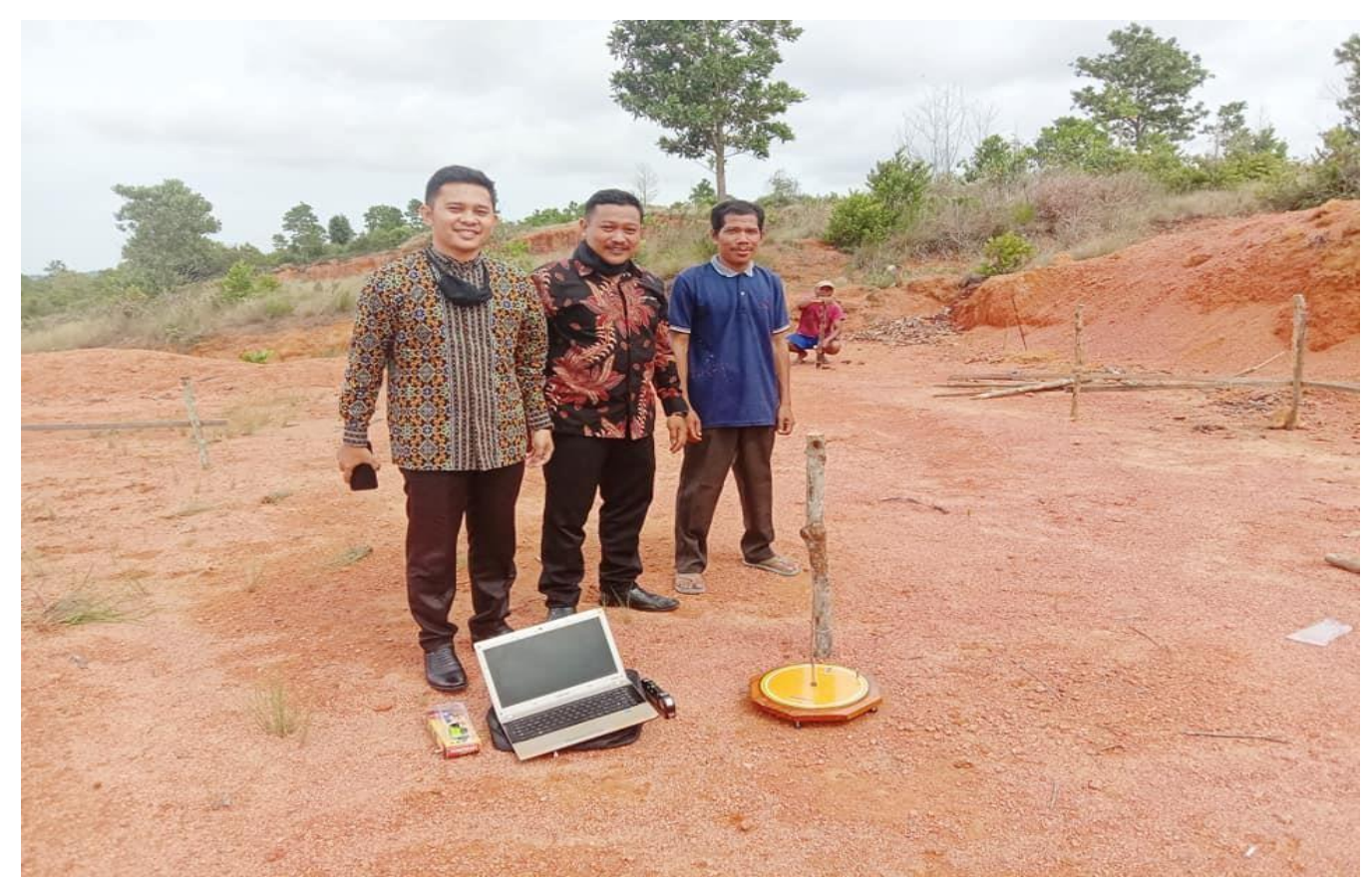

Gambar 5. Foto Bersama Ketua Pondok Pesantren Syaikh Zainuddin

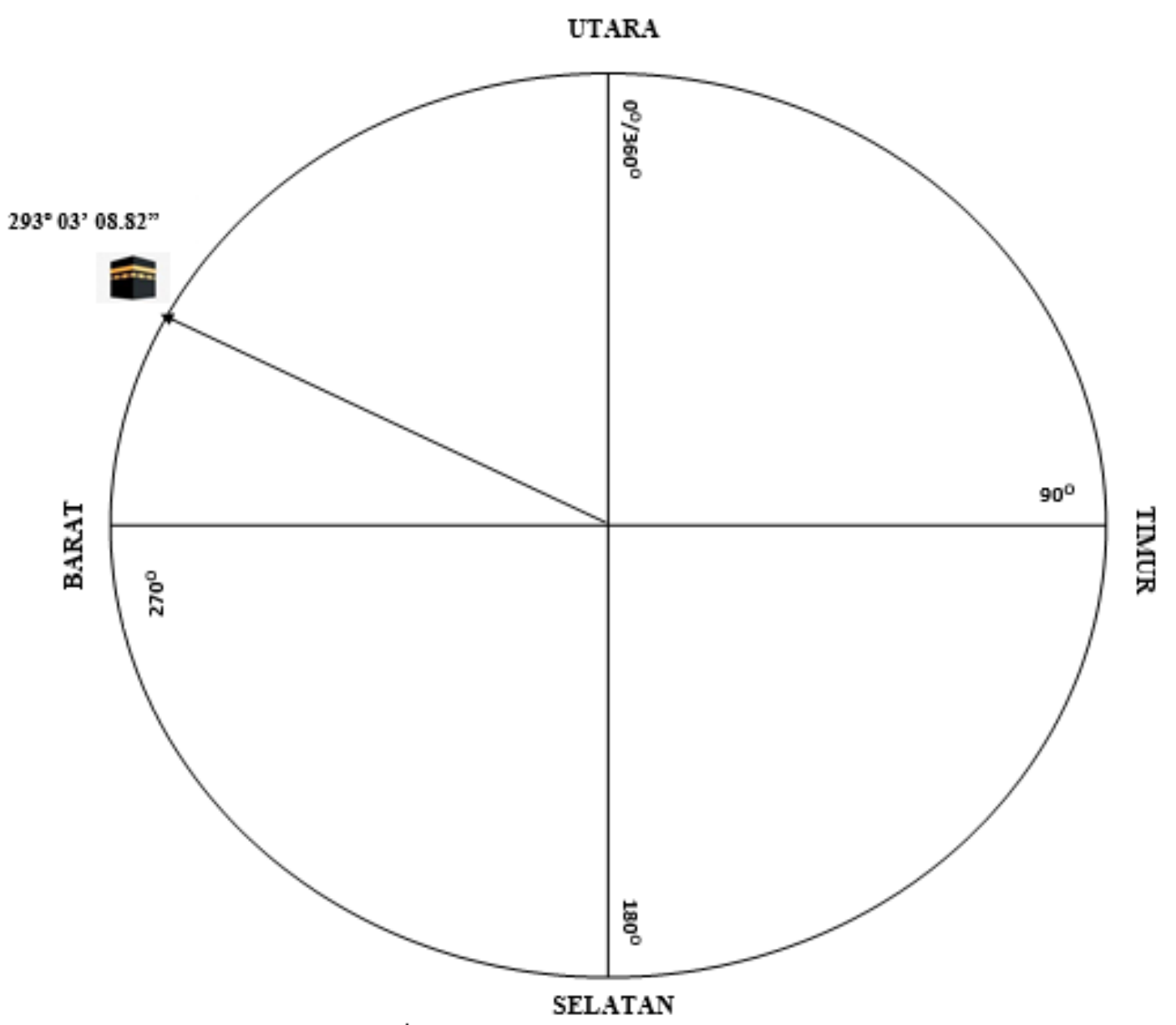

Gambar 6. Posisi Arah Kiblat Masjid Syaikh Zainuddin 


\section{Kesimpulan}

Pondok Pesantren Syaikh Zainuddin Nahdlatul Wathan Bintan merupakan Pondok Pesantren yang berada di bawah naungan organisasi Nahdlatul Wathan yang didirikan oleh Maulana Syaikh TGKH. Muhammad Zainuddin Abdul Madjid, seorang Pahlawan Nasional dari Lombok - Nusa Tenggara Barat. Pondok ini merupakan kategori pondok baru dan sedang membangun berbagai macam fasilitas pondok termasuk masjid. Pengukuran arah kiblat Masjid Syaikh Zainuddin dilakukan pada tanggal 11 Februari 2021 dengan data lintang tempat $01^{\circ} 0.84^{\prime}$ LS, bujur tempat $104^{\circ} 30.67^{\prime}$ BT menggunakan Instrumen Falak yaitu Aulatis. Posisi arah kiblat Masjid Syaikh Zainuddin adalah $23^{\circ} 03^{\prime}$ 8.82" dari titik Barat miring ke arah Utara atau 66 56' 51.18" dari titik Utara miring ke arah Barat atau Azimut Kiblat 293 03' 08.82" UTSB (Utara Timur Selatan Barat). Pengukuran arah kiblat Masjid Syaikh Zainuddin disaksikan langsung oleh Bapak Saepuddin, M.Ag selaku Ketua Pondok Pesantren Syaikh Zainuddin Nahdlatul Wathan Bintan. Diharapkan kedepannya semakin banyak para pengurus masjid yang peduli akan pentingnya menghadap arah kiblat secara presisi demi memantapkan keyakinan dalam beribadah.

\section{Saran}

Pengukuran arah kiblat terhadap masjid, mushalla, rumah dan tempat umum yang digunakan sebagai tempat beribadah perlu dilakukan, karena menghadap kiblat adalah salah satu syarat sah shalat. Pengukuran arah kiblat masjid, mushalla, rumah dan tempat lainnya adalah dalam rangka memantapkan keyakinan beribadah. Badan Kemakmuran Masjid, Mushalla dan para pengelola tempat umum lainnya diharapkan memiliki kesadaran akan pentingnya menghadap kiblat demi kenyamanan masyarakat dalam beribadah. Pemerintah juga hendaknya memfasilitasi para ahli falak dengan alat yang lebih canggih dalam rangka mendapatkan hasil pengukuran yang lebih presisi.

\section{Ucapan Terimakasih}

Terima kasih kami ucapkan kepada semua pihak yang telah memberikan dukungan dan peran baik dalam bentuk materil maupun moril. Terima kasih kepada Bapak Saepuddin, M.Ag selaku pimpinan Pondok Pesantren Syaikh Zainuddin Nahdlatul Wathan Bintan.

\section{Referensi}

Angkat, M. Arbisora. (2016). Studi Analisa Penentuan Arah Kiblat Masjid Raya Al-Mashun Medan, Al Marshad: Jurnal Astronomi Islam dan Ilmu-Ilmu Berkaitan, 2 (1).

Angkat, M. Ali Romdhon dan M. Arbisora. (2021) Bintang Panjer Sore Sebagai Petunjuk Arah Kiblat Oleh Kelompok Nelayan "Mina Kencana" Desa Jambu Kecamatan Mlonggo Kabupaten Jepara. Al Marshad: Jurnal Astronomi Islam dan Ilmu-Ilmu Berkaitan, 7(1).

Ash-Shiddieqy, T.M.H. (2003). Mutiara Hadits 3, cet. I. Semarang: Pustaka Riski Putra

Azhari, S. (2007). llmu Falak, cet. II. Yogyakarta: Suara Muhammadiyah.

Departemen Agama Republik Indonesia. (2005). Al-Qur'an dan Terjemahnya. Bandung: PT Syamil Cipta Media.

Profil Nahdlatul Wathan Kepri. Retrieved from https://nwkepri.com/profile/, diunduh tanggal 18 Februari 2021 pukul 19.00 WIB. 
Izzuddin, A. (2007). Fiqh Hisab Rukyah, (Menyatukan NU \& Muhammadiyah dalam Penentuan Awal Ramadhan, Idul Fitri, dan Idul Adha). Jakarta: Penerbit Erlangga.

Izzuddin, A. 2006). Ilmu Falak Praktis (Metode Hisab-Rukyah dan Solusi Permasalahannya). Semarang: Kamala Grafika.

Ma'arif, S. Software Aulatis (Alat Ukur Kiblat Praktis). (Lembaga Falakiyah PCNU Kab. Mojokerto)

Saepuddin. (2021). Ketua Pondok Pesantren Syaikh Zainuddin Nahdlatul Wathan Bintan. Wawancara Pribadi.

Zuhaili, W. (2010). Fiqh Imam Syafi'i, terj Muhammad Afifi dan Abdul Hafiz dari “Al-FiqhuAsy-Syafi'il Al-Muyassar". Jakarta: Almahira. 